\title{
Relative Cohort Size and Fertility in Latin America and the Caribbean: A Panel Data Approach
}

\author{
Linlan Xiao ${ }^{1} \&$ Michael Shields ${ }^{1}$ \\ ${ }^{1}$ Department of Economics, Central Michigan University, Michigan, USA \\ Correspondence: Linlan Xiao, Assistant Professor, Department of Economics, Central Michigan University, Mount \\ Pleasant, Mich. 48859, USA. E-mail: xiao11@cmich.edu
}

Received: July 31, 2014

Accepted: August 18, 2014

Online Published: August 30, 2014

doi:10.5430/rwe.v5n2p135

URL: http://dx.doi.org/10.5430/rwe.v5n2p135

\begin{abstract}
Latin America has experienced a considerable decline in fertility over the past decades. The total fertility rate at region level was 4.57 in 1975 and fell to 2.29 in 2012. In this study, we examine effect of cohort size on fertility rate to test the applicability of the Easterlin hypotheses. According to the Easterlin hypotheses the income of young adults relative to the income of their parents is an important determinant of fertility. A major factor influencing relative income is relative cohort size. Persons born in large cohorts face greater difficulty in finding employment than persons born in small cohorts due to increased competition and consequently earn less, and, as a result have fewer children. We introduce relative cohort size into panel data models with the total fertility rate being estimated as a function of cohort size, the labor force participation rate of women, the infant mortality rate, the lagged total fertility rate, and the percent of the population that is urban. The results suggest that the Easterlin hypothesis holds in this region but the effect is weak. On the other hand, advanced medical technology hence decrease in infant mortality rate strongly affect fertility.
\end{abstract}

Keywords: cohort size, fertility, Easterlin, Latin America, Caribbean

\section{Introduction}

Early in 1961, Richard Easterlin presented his basic argument that changing relative cohort sizes hence relative "male relative income" produced the baby boom and then baby bust. Later in 1978, Easterlin expanded his works and claimed that changing relative cohort size also explained many of the puzzling phenomena, such as trends of marriage, divorce, education, female labor force participation, etc. in the United States, known as the Easterlin effect. The Easterlin hypothesis states that the aspirations of young adults as to what constitutes the good life were formed by their experience as a child based on the income of their parents. The income of young adults relative to the income they experienced while living with their parents is hypothesized to be an important determinant of fertility. During periods when there are a large number of young adults relative to older adults of working age, the young adults face stiff competition for employment which suppresses their relative income. According to this hypothesis, young adults react to this low relative income by delaying family formation and having fewer children.

The Easterlin hypothesis has attracted much attention for the past decades. Many studies have used empirical data to test Easterlin effect - see, Macunovich (1998), Pampel and Peters (1995), and Waldorf and Byun (2005), for a review of the literature. The results are mixed with support as well as rejection for the Eaterlin effect, or simply inclusion. For example, Baird (1987) studied the fertility change in Western Europe during the years 1950-1981 and his result supported the Esterlin hypothesis. Jeon and Shields (2005) applied panel data analysis and temporal causality test and found strong evidence supporting the Easterlin hypothesis for higher-income OECD countries. Pampel (1993) was more skeptical about the Easterlin hypotheses. In his study, while estimates from pooled cross-sectional time-series model showed a positive effect of relative cohort size on fertility, the relationship was weak in single countries. Wright and Maxim (1987) examined the relationship between relative cohort size and the fertility rate in Canada during the years 1922-1984 by applying an age-period-cohort analysis method, their result indicated that larger Canadian cohorts appeared to have higher relative fertility rates hence the Easterlin hypothesis did not hold for the Canadian situation. Abeysinghe (1991) measured Canadian fertility rate and relative cohort size during the years 1921-1988, using cointegration techniques the results showed that there was no equilibrium relationship between them. It is noticed that in current literature most studies investigate the Easterlin effect of relative cohort size on fertility for developed countries that have completed the demographic transition, while few studies has focused on 
developing countries. Macunovich (2000) studied the effect of relative cohort size on fertility rate for nearly 200 countries at five year intervals from 1950 through 1995, including developed countries as well as developing countries like Belize, Costa Rica, El Salvador, Guatemala, Honduras, Mexico, Nicaragua and Panama in Central America and the Caribbean which were passing through the demographic transition. The empirical evidence in this study suggested that the Easterlin effect did hold in developing countries during the period 1950-1995. However, the relative cohort size in Macunovich (2000) was approximated as the ratio of 15 to 24 year olds to those aged 25 to 59 which was not a very good measure since "the younger and older member of the 25 to 59 age group are fairly good substitutes for those ages 15-24"(Endnotes Macunovich (2000)); in addition, the empirical evidence was based on study during 1950-1995 while countries in the Latin America and the Caribbean still experience the demographic transition after 1995. In our study, we extend Macunovich (2000) by testing the Easterlin hypothesis for thirty four countries in Latin America and the Caribbean using more recent data which spans from 1975 to 2012. We apply panel data analysis so that individual country effect can be taken into account.

The next section of the paper contains a discussion of the theory behind the Easterlin hypotheses for both developed and developing countries. Section three discussed the demographic transition in Latin America and the Caribbean. In section four, data and the variables are discussed. We also discuss visual inspection along with the estimate results of panel regression. A brief final conclusion is included in the last section.

\section{The Easterlin Hypothesis and the Theory of Demographic Transition}

The Easterlin hypothesis was developed by Easterlin to explain the baby boom in the United States. The basic idea was that the aspirations of young adults as to the style of life to which they aspire was largely formed when they were adolescents still living in their parents' home. The income of young adults relative to the income which they experienced in their parent's home is a major factor in their childbearing plans. As Easterlin pointed out, during the baby boom relative income was high for several reasons. First, they grew up during the great depression when incomes were suppressed, second, since fertility was low during the great depression, there were relatively fewer young adults competing for entry level jobs hence their wage rates increased, and, finally these young adults had an educational advantage over their parents. As a result of these three factors, young adults could easily achive the income of their parents, concentrating on child bearing because only one parent had to work to experience the good life. As a result they had many children, the "baby boom' who a generation later had to compete for entry level jobs. Since the size of their cohort, relative to that of their parents was high, they had far more difficulty finding suitable employment. Consequently, they delayed family formation, had fewer children, and both parents had to work if they were to achieve the incomes of their parents.

The U.S. can be described as a country that has already completed the demographic transition. Developing countries, on the other hand, are still undergoing the transition from higher to lower fertility. Consequently demographic trasition should be taken in account when investigating the fertility rate change in these countries. Macunovich (2000) extended the Easterlin hypothesis in order to apply it to both developed and developing countries. She combined the Easterlin hypothesis with the theory of the demographic transition. The theory of the demographic transition relies heavily on functionalism (See Thompson, 1929 and Notestein, 1949). Mortality rates before the transition were high. In order to be viable a society needed to encourage high fertility to offset this high mortality. Social norms and mores were developed that encouraged high fertility. Industrialization and the resulting modernization of a society are thought to first reduce mortality because of higher income and better medical technology. Fertility remains high because social norms and mores were developed in earlier epochs of high mortality when high fertility was necessary for society's survival. However, society will adjust over time to the lower mortality rates by developing new norms and mores consistent with lower mortality. This process will eventually cause fertility to fall. Macunovich (2000) argued that relative cohort size influenced the timing of this decline in fertility. The pace of fertility decline in the demographic transition is an important empirical question and whether it could be quickened by policy measures, such as providing more education for females is important for public policy.

While transition theory implies that fertility will eventually decline with modernization, it does not necessarily imply that the pace of this decline and the timing of its onset are sufficiently large enough or early enough to assure the future prosperity of society. Hence, an understanding of when and how rapidly fertility will decline and how it will respond to policy measures is important for formulating population policy.

Macunovich (2000) extended the Easterlin hypothesis to explain the timing of the onset of the demographic transition. In the initial stage of the transition, modernization resulted in higher income and falling mortality, created an excess supply of surviving children. Parents may recognize the existence of this excess supply but not take any action to reduce births. Macunovich (2000) argued that the timing of the onset of fertility decline depended on both the duration and the magnitude of the excess supply of births. Initially, the excess supply largely came from the decline in mortality. Eventually, however, relative cohort size began to rise due to the increased probability of 
survival through childhood decline in mortality. (Note 1) If the Easterlin hypothesis was applicable to the economies of developing countries, this reduced the relative income of young adults resulting in an increase in the excess supply of births. Once this excess supply reached some critical level parents began to plan the size of their family and take action to reduce fertility.

The decline in mortality would eventually result in an increase in relative cohort size. The mechanism for which relative cohort size to affect fertility is slightly different in developing countries which are still undergoing the demographic transition, than in developed countries that have already completed the transition. In developed countries, increases in the supply of young workers causing crowding in the entry-level job markets, which suppress the relative wages of young adults. In developing countries, this labor market crowding may not suppress wages because the labor markets may not be functioning well. Wage rates might be set more by tradition and subsistence requirements within a dualistic labor market than by market forces. However, higher relative cohort size would still place economic stress on young adults through higher entry-level unemployment and less access to land. Consequently fertility would fall.

\section{Demographic Transition in Latin America and the Caribbean}

Countries in Latin America and the Caribbean have been experiencing the demographic transition from high levels of mortality and fertility to low levels over the past half century. The region level infant mortality rate was around 100 per thousand births during 1960s, since then it declined consistently and in 2012 the region level dropped to approximately 19 per thousand births. The total fertility rate also displayed a declined trend dropping from around 5 children per woman during 1960s to 2.29 children per woman in 2012. And as discussed in Saad (2011), "For the next four decades, (the total fertility rate) it is expected to remain below but close to the replacement level of 2.1 children per woman." (page3, Saad 2011) As fertility rate plays a very important role in the population and economic dynamics in Latin America and the Caribbean it has drawn much attention in the literature. Researchers investigate factors possibly affecting the total fertility rate as well as effect of fertility on other variables. For example, Rosero (1996) examined the role of marriage patterns in the fertility transition in Latin America. The evidence from census data suggested that in the region as a whole nuptiality did not substantially affect the total fertility rate. Martin and Juarez (1995) studied the impact of women's education on fertility in nine Latin American countries using data from Demographic and Health Surveys. There existed wide fertility gap between educational strata - the better educated women had small families of 2-3 children, whereas women with no education had large families of 6-7 children. The regression results suggested that reproductive preferences do not differ much among educational groups, while contraceptive behavior differed widely. Palloni and Rafalimanana (1999) investigated the relationship between infant and child mortality and fertility in Latin American countries during 1920-1990. The evidence from different data sets consistently suggested that infant mortality positively affected fertility; however the effects were very small implying that the infant mortality was of modest importance in explaining the declined trend of fertility. Cruces and Galiani (2007) studied the causal effect of fertility on female labor supply in two middle-income Latin American countries Argentina and Mexico, using both least square regression and a series of instrumental variable regression the results indicated that there existed strong negative correlation between fertility and female labor supply.

Studies have shown that many different factors could affect the dynamics of fertility in Latin America and the Caribbean, either positively or negatively. In this study, we focus on investigating the effect of relative cohort size on fertility in this region, i.e. examining the Easterlin hypothesis.

\section{Data and Empirical Methods}

This paper uses data for thirty four countries in Latin America and the Caribbean over the period from 1975 through 2012. (Note 2) The data come from World Development Indicators (2013). The variables include the total fertility rate (birth per woman, in short TFR), relative cohort size (hence RCS), the infant mortality rate, the percent of the population classified as urban, and the labor force participation rate of women. The RCS is calculated by dividing population aged between fifteen and twenty-nine by population aged between thirty and sixty-four. The mortality rate is defined as the ratio of infant deaths per 1000 live births. The variable urban population is defined as percentage of a country's urban population living in that country's largest metropolitan area. And the labor force participation rate of women is a ratio of female workers over female population age between fifteen and sixty four.

\subsection{A Simple Visual Inspection}

Table 1 reports the average values of each variable cross 34 countries for each year. Clearly the regional levels of infant mortality rate and total fertility rate have been decreasing dramatically over the last 38 years. Specifically infant mortality rate fell from 64.52 per 1000 births in 1975 to 17.38 per 1000 births in 2012, by about seventy three percent; total fertility rate dropped from 4.57 in 1975 to 2.29 in 2012, by about fifty percent, indicating that countries in Latin America and the Caribbean are experiencing demographic transition during our sample period. Interestingly, 
we find that the regional level of relative cohort size also displays decline pattern. During late 1970 and early 1980 , the relative cohort size was mostly higher than 2, then it started to decline and the regional level has been consistently below 1 ever since 2002. On the other hand, the urban population declined from 50.7 to 37.92 by twenty five percent, and the female labor force participation rate rose from 39.43 to 57.18 by approximately four five percent.

The pattern we observe above implies that clearly infant mortality rate plays an important role on the dynamics of fertility - they are positively correlated, which is consistent with theory of demographic transition. On the other hand, relative cohort size does not show strong negative effect on fertility if there is any.

Table 1. Summary statistics by year: average values cross 34 countries

\begin{tabular}{|c|c|c|c|c|c|}
\hline Year & $\begin{array}{ll}\text { Total Fertility } \\
\text { Rate }\end{array}$ & $\begin{array}{l}\text { Relative Cohort } \\
\text { Size } \\
\end{array}$ & $\begin{array}{ll}\text { Female } & \text { Labor } \\
\text { Force } & \\
\end{array}$ & $\begin{array}{l}\text { Urban } \\
\text { Population }\end{array}$ & $\begin{array}{l}\text { Infant } \\
\text { Mortality Rate }\end{array}$ \\
\hline 1975 & 4.57 & 1.99 & 37.43 & 50.70 & 64.52 \\
\hline 1976 & 4.46 & 2.17 & 37.79 & 50.54 & 62.83 \\
\hline 1977 & 4.36 & 2.69 & 38.05 & 50.46 & 60.34 \\
\hline 1978 & 4.26 & 6.19 & 38.38 & 50.31 & 57.89 \\
\hline 1979 & 4.16 & 1.63 & 38.72 & 50.22 & 55.58 \\
\hline 1980 & 4.07 & 14.61 & 39.08 & 50.11 & 53.33 \\
\hline 1981 & 3.99 & 2.69 & 39.44 & 49.94 & 51.31 \\
\hline 1982 & 3.90 & 2.01 & 39.78 & 49.69 & 49.68 \\
\hline 1983 & 3.83 & 1.82 & 40.09 & 49.46 & 47.83 \\
\hline 1984 & 3.75 & 1.74 & 40.40 & 49.24 & 45.36 \\
\hline 1985 & 3.67 & 1.68 & 40.81 & 49.10 & 43.77 \\
\hline 1986 & 3.60 & 1.63 & 41.03 & 48.94 & 42.19 \\
\hline 1987 & 3.53 & 1.58 & 41.42 & 48.81 & 40.65 \\
\hline 1988 & 3.46 & 1.54 & 42.04 & 48.72 & 39.17 \\
\hline 1989 & 3.40 & 1.49 & 42.39 & 48.60 & 37.77 \\
\hline 1990 & 3.34 & 1.44 & 42.58 & 48.45 & 35.88 \\
\hline 1991 & 3.27 & 1.38 & 43.05 & 48.18 & 34.61 \\
\hline 1992 & 3.21 & 1.32 & 43.44 & 47.88 & 33.35 \\
\hline 1993 & 3.15 & 1.27 & 43.89 & 47.58 & 32.17 \\
\hline 1994 & 3.09 & 1.22 & 44.16 & 47.30 & 31.04 \\
\hline 1995 & 3.02 & 1.18 & 44.40 & 47.05 & 29.95 \\
\hline 1996 & 2.96 & 1.15 & 44.66 & 46.81 & 28.91 \\
\hline 1997 & 2.90 & 1.12 & 45.24 & 46.59 & 27.87 \\
\hline 1998 & 2.84 & 1.09 & 45.76 & 46.40 & 26.85 \\
\hline 1999 & 2.78 & 1.06 & 46.25 & 46.24 & 25.90 \\
\hline 2000 & 2.73 & 1.04 & 46.39 & 46.16 & 25.00 \\
\hline 2001 & 2.67 & 1.01 & 46.86 & 46.09 & 24.17 \\
\hline 2002 & 2.63 & 0.98 & 47.32 & 46.08 & 23.43 \\
\hline 2003 & 2.58 & 0.96 & 47.77 & 46.09 & 22.7 \\
\hline 2004 & 2.54 & 0.93 & 48.22 & 46.13 & 22.03 \\
\hline 2005 & 2.51 & 0.91 & 48.89 & 46.19 & 21.37 \\
\hline 2006 & 2.47 & 0.90 & 49.45 & 46.30 & 20.75 \\
\hline 2007 & 2.43 & 0.88 & 49.88 & 46.42 & 20.14 \\
\hline 2008 & 2.40 & 0.87 & 50.32 & 46.56 & 19.55 \\
\hline 2009 & 2.37 & 0.85 & 56.38 & 46.53 & 18.99 \\
\hline 2010 & 2.34 & 0.84 & 56.67 & 37.25 & 18.91 \\
\hline 2011 & 2.32 & 0.82 & 56.89 & 37.24 & 17.89 \\
\hline 2012 & 2.29 & 0.81 & 57.18 & 37.20 & 17.38 \\
\hline
\end{tabular}

Total fertility rate (births per woman), Relative cohort size (population ages 15-29 over population ages 30-64), female labor participation rate (\% of female population ages $15-64)$, urban population (\% of total population), and infant mortality rate (per 1,000 live births). 
Table 2 reports the average values of each variable over 1975 to 2012 for 34 countries. The average fertility rate is 3.21 for the region as a whole and rates show significant variations cross countries. Among the 34 countries, Guatemala has the highest fertility rate of 5.23 and Cuba has the lowest rate of 1.76. Meanwhile the average mortality rate is 34.14 per 1000 births; Haiti has the highest rate of 94.27 while Cuba has the lowest rate of 10.66. This is not surprising as Cuba is at a very advance stage of transition while Guatemala and Haiti are still at the moderate stage. The average ratio of relative cohort size is 1.32 indicating that the size of younger generation is about thirty percent larger than that of older generation group. Grenada has the highest younger generation portion which is 3.84 and Argentina has the lowest relative cohort size of 0.65 . The average female labor force rate is 45.78 with the highest percentage of 65.79 in Bahamas and the lowest of 33.96 percent in Puerto Rico. On average, about 47.89 percent of the populations live in urban with the lowest percentage of 13.22 in Brazil and the highest of 99.88 percent in Antigua and Barbuda.

Table 2. Summary statistics by country: average values over 1975-2012

\begin{tabular}{|c|c|c|c|c|c|}
\hline Country & $\begin{array}{l}\text { Total Fertility } \\
\text { Rate }\end{array}$ & $\begin{array}{l}\text { Relative Cohort } \\
\text { Size }\end{array}$ & $\begin{array}{l}\text { Female Labor } \\
\text { Force }\end{array}$ & $\begin{array}{l}\text { Urban } \\
\text { Population }\end{array}$ & $\begin{array}{l}\text { Infant } \\
\text { Mortality Rate }\end{array}$ \\
\hline Antigua and & 2.20 & 1.20 & $\mathrm{n}$ & 99.88 & 14.01 \\
\hline \multicolumn{6}{|l|}{ Barbuda } \\
\hline Aruba & 2.09 & 0.75 & $\mathrm{n}$ & 60.54 & $\mathrm{n}$ \\
\hline The Bahamas & 2.46 & 0.78 & 65.79 & 85.79 & 19.08 \\
\hline Barbados & 1.86 & 0.91 & 63.52 & 97.44 & 18.79 \\
\hline Belize & 4.31 & 1.63 & 39.25 & 48.76 & 34.17 \\
\hline Bolivia & 4.61 & 1.18 & 59.89 & 28.58 & 76.01 \\
\hline Brazil & 2.86 & 0.89 & 51.68 & 13.22 & 45.45 \\
\hline Chile & 2.38 & 0.77 & 36.45 & 40.38 & 17.00 \\
\hline Colombia & 3.11 & 1.05 & 35.20 & 21.92 & 29.18 \\
\hline Costa Rica & 2.85 & 0.84 & 37.01 & 48.08 & 15.14 \\
\hline Cuba & 1.76 & 0.74 & 38.48 & 26.97 & 10.66 \\
\hline Dominica & 3.44 & 1.20 & 46.27 & 36.27 & 43.54 \\
\hline \multicolumn{6}{|l|}{ Republic } \\
\hline Ecuador & 3.66 & 0.99 & 39.38 & 28.32 & 42.28 \\
\hline EI Salvador & 3.70 & 1.81 & 43.74 & 36.14 & 44.05 \\
\hline Grenada & 3.32 & 3.84 & $\mathrm{n}$ & 99.86 & 15.21 \\
\hline Guatemala & 5.23 & 1.51 & 42.42 & 21.53 & 56.44 \\
\hline Guyana & 2.90 & 2.53 & 40.11 & 67.08 & 42.84 \\
\hline Haiti & 4.89 & 1.31 & 56.97 & 54.96 & 94.27 \\
\hline Honduras & 4.80 & 1.42 & 42.16 & 28.24 & 43.87 \\
\hline Jamaica & 2.99 & 1.61 & 62.92 & 47.36 & 24.01 \\
\hline Mexico & 3.39 & 1.20 & 37.97 & 24.47 & 33.97 \\
\hline Nicaragua & 4.34 & 1.58 & 39.84 & 31.93 & 48.17 \\
\hline Panama & 3.16 & 0.94 & 42.44 & 57.24 & 26.17 \\
\hline Paraguay & 4.20 & 1.18 & 50.27 & 53.36 & 34.30 \\
\hline Peru & 3.69 & 1.03 & 53.6 & 39.13 & 43.83 \\
\hline Puerto Rico & 2.14 & 0.81 & 33.96 & 62.65 & $\mathrm{n}$ \\
\hline St. Lucia & 3.21 & 1.92 & 45.13 & 35.85 & 19.76 \\
\hline $\begin{array}{l}\text { St. Vin. and the } \\
\text { Gren. }\end{array}$ & 2.96 & 3.13 & 48.66 & 60.68 & 27.23 \\
\hline Suriname & 3.03 & 2.07 & 35.94 & 73.19 & 35.81 \\
\hline $\begin{array}{l}\text { Trinidad and } \\
\text { Tobago }\end{array}$ & 2.38 & 1.06 & 47.46 & 41.65 & 28.11 \\
\hline Uruguay & 2.42 & 0.66 & 50.68 & 55.27 & 21.76 \\
\hline Venezuela, RB & 3.32 & 0.88 & 41.27 & 16.11 & 24.12 \\
\hline $\begin{array}{l}\text { Virgin } \\
\text { Islands(U.S.) }\end{array}$ & 2.6 & 0.79 & 46.88 & 48.13 & \\
\hline
\end{tabular}

Total fertility rate (births per woman), Relative cohort size (population ages 15-29 over population ages 30-64), female labor participation rate (\% of female population ages $15-64)$, urban population (\% of total population), and infant mortality rate (per 1,000 live births). 


\subsection{Panel Data Regressions}

To further investigate whether or not the Easterlin effect holds for these developing countries in Latin America and the Caribbean, four panel data models are considered. Specifically, in the first model, the total fertility rate (TFR) is estimated as a function of relative cohort size (RCS), and the infant mortality rate. The second model is a copy of Macunovich (2000)'s study by introducing the lag of TFR to control for many other factors which are thought to play a role in TFR determination. In the third model, we include the proportion of the population classified as urban since it is possible that residences of urban areas tend to have fewer children because making a large family is more expensive than in rural areas. And in the last model, we consider adding the female labor participation rate as it is thought to play a role in determining the fertility rate.

In all four models, we use first differences in the value of each variable instead of the level variables themselves. The reasons are twofold. First, as Macunovich (2000) pointed out, "the levels of RCS will be lower in societies where the level of fertility has been low, or where the level of infant mortality has been high, creating a potential for spurious correlation among levels because of a relationship slowing from past values of fertility and infant mortality to RCS". Hence "it is appropriate here to examine only changes in TFR, RCS, and infant mortality". (page 254, Macunovich, 2000). Second, in our study we use panel data hence there exists unobserved country fixed effect. Including the fixed effect would result in biased and inconsistent estimates. By taking the first differences, we are able to remove these unobserved country fixed effect. The first differences are calculated by subtracting the value in time $\mathrm{t}-1$ form its value in time t. In addition, we use cumulative changes (Note 3) in infant mortality following Macunovich (2000) which claimed "In the case of infant mortality, fertility is expected to respond to the cumulative effect of changes in infant mortality, rather than to changes in only the most recent period."(page 254, Macunovich, 2000).

Table 3 provides estimated effects of relative cohort size, infant mortality, and the lagged total fertility rate on TFR (the first two models). In the first model, the coefficients of RCS and infant mortality are both positive and statistically significant at the one percent level. The positive sign of coefficient for RCS suggests that the Easterlin effect does not hold for developing countries in Latin America and the Caribbean, whereas infant mortality rate positively affects TFR which is consistent with the fact that these countries are undergoing demographic transition. However we have to admit that many other factors which also affect fertility are omitted in this model resulting in bias estimates. To take into account those factors the lagged TFR is introduced in the second model. The sign of coefficient for RCS becomes negative and insignificant. However, the sign of coefficient for mortality rate is still positive and highly significant, suggesting that infant mortality rate does play an important role in dynamics of TFR. The coefficient of lagged TFR is positive, relatively very large, and statistically significant at one percent level. The positive estimated coefficient of lagged TFR indicates that the declining fertility rate in past years has a strong effect on subsequent fertility, supporting the idea of a "cascade" effect. We notice that when lagged TFR is controlled, the value of adjusted R-squared increases dramatically, suggesting that this variable is very important.

Table 3. Regression coefficients, with and without lagged total fertility rate, of the effects of changes in relative cohort size and infant mortality on changes in the total fertility rate

\begin{tabular}{lll}
\hline & Without lagged total fertility & With lagged total fertility \\
\hline Relative cohort size & 0.0601 & -0.0025 \\
& {$[3.02]^{* * *}$} & {$[-0.76]$} \\
Infant mortality & 0.033 & 0.0012 \\
& {$[32.19]^{* * *}$} & {$[5.01]^{* * *}$} \\
Lagged TFR & & .9445 \\
& & {$[189.05]^{* * *}$} \\
Adjusted R-squared & .5028 & .9857 \\
\hline
\end{tabular}

Note: All variables are expressed as first differences. Total fertility rate (TFR) is the number of births per women. Relative cohort size (RCS) is the ratio of population aged 15-29 to population aged 30-64. Infant mortality rate is the cumulative changes from 1975 to year t. Lagged TFR is TFR at time t-1. The t-statistics are in brackets.

*** Significant at one percent level, ** Significant at five percent level, *Significant at ten percent level.

Table 4 reports the estimation result for the last two models. In both models, the coefficients of RCS are negative and at least statistically significant at the ten percent level, implying that the Easterlin hypothesis holds in these developing countries; the coefficients for infant mortality rate as well as the lagged TFR are positive and highly significant, suggesting that these two variables positively affect the TFR. In the third model, the coefficient of urban 
population is positive and highly significant, suggesting that people living in large cities tend to have more children than those living in rural area. We add female labor participation rate variable in the fourth model to examine whether increase of female labor participation rate would decrease TFR. The sign of coefficient for female labor participation is positive; however it is statistically insignificant implying that this variable does not play an important role in TFR determination. For both models, the values of adjusted R-squared are very high and close to each, suggesting that the entire group of independent variables explain TFR well, and whether or not controlling female labor force participation does not make much difference.

Table 4. Regression coefficients, with urban population and with urban population along with female labor participation rate, of the effects of changes in relative cohort size and infant mortality on changes in the total fertility rate

\begin{tabular}{lll}
\hline & $\begin{array}{l}\text { Without female labor } \\
\text { participation rate }\end{array}$ & $\begin{array}{l}\text { With female labor participation } \\
\text { rate }\end{array}$ \\
\hline Relative cohort size & -.0056 & -0.0123 \\
& {$[-1.67]^{*}$} & {$[-3.11]^{* * *}$} \\
Infant mortality & 0.0015 & 0.0021 \\
& {$[6.02]^{* * *}$} & {$[8.01]^{* * *}$} \\
Lagged TFR & 0.9353 & 0.9251 \\
& {$[179.70]^{* * *}$} & {$[172.84]^{* * *}$} \\
Urban population & 0.0031 & 0.0026 \\
& {$[6.15]^{* * *}$} & {$[5.73]^{* * *}$} \\
Female labor participation & & .0001 \\
& & {$[0.64]$} \\
Adjusted R-squared & .9862 & .9885 \\
\hline
\end{tabular}

Note: All the variables are expressed as first differences. Total fertility rate (TFR) is the number of births per women. Relative cohort size (RCS) is the ratio of population aged 15-29 to population aged 30-64. Infant mortality rate is the cumulative changes from 1975 to year t. Lagged TFR is the TFR at time t-1. The urban population is the ratio of urban population over the total population. And the labor force participation rate of women is a ratio of female workers over female population aged15-64. Standardized coefficient estimates are in italics, and t-statistics are in brackets.

*** Significant at one percent level, ** Significant at five percent level, *Significant at ten percent level.

Overall, we find for all four models, the signs of coefficients for infant mortality rate, lagged TFR, and urban population are consistently positive. The coefficients of these variables are highly statistically significant, suggesting that these variables do play an important role in TFR determination, and they all positively affect current TFR. When lagged TFR is introduced in the model, the coefficients of RCS are always negative and most time statistically significant at least at the ten percent level, suggesting that relative cohort size negatively affects total fertility rate, but the effect is not as strong as other three variables. Female labor force participation does not play an important role in TFR determination.

\section{Conclusions}

The Easterlin hypothesis is an exercise in contradiction. Current studies in the literature suggest that the hypotheses work better with macro data than with micro data. In addition, there is contradictory evidence about the strength of the Easterlin hypotheses for countries outside the U.S. While most studies examine the Easterlin effect in developed countries, few studies has been focusing on developing countries undergoing demographic transition. Our study for countries in Latin America and the Caribbean showed that relative cohort size does negatively affect total fertility rate which is consistent with the finding in Macunovich (2000). However, the effect is weak implying that improving medical technology hence decreasing infant mortality rate plays a very important role in the dynamics of total fertility rate. Future study could be adding female education variable to examine effect of providing more education for female on fertility in these countries.

\section{References}

Abeysingle, T. (1991). On testing Easterlin's hypothsis using relative cohort size as proxy for relative income: an analysis of Canadian data. Journal of Population Economics, 4, 53-69. http://dx.doi.org/10.1007/BF00160368 
Baird, A. J. (1987). A note on the Easterlin model of fertility in northwestern Europe and the United States: 1950-1981. International Journal of Comparative Sociology, 23(1-2), 57-68. http://dx.doi.org/10.1177/002071528702800105

Cruces, G., \& Galiani, S. (2007). Fertility and female labor supply in Latin America: new causal evidence. Labour Economics, 14(3), 565-573. http://dx.doi.org/10.1016/j.labeco.2005.10.006

Easterlin, R. A. (1968). Population, labor force, and long swings in economic growth. Columbia University Press for NBER, New York.

Joen, Y., \& Shields, M. P. (2005). The Easterlin hypotheses in the recent experience of OECD countries: panel-data approach. The Journal of Population Economics, 18, 1-13.

Macunovich, D. J. (1998). Fertility and the Easterlin hypothesis: An assessment of the literature. Journal of Population Economics, 11(1), 53-111. http://dx.doi.org/10.1007/s001480050058

Macunovich, D. J. (2000). Relative cohort size: source of a unifying theory of global fertility transition? Population and Development Review, 26(2), 235-261. http://dx.doi.org/10.1111/j.1728-4457.2000.00235

Martin, T. C., \& Juarez, F. (1995). The impact of women's education on fertility in Latin America: searching for explanations. International Family Planning Perspectives, 21(2), 52-80. http://dx.doi.org/10.2307/2133523

Palloni, A., \& Rafalimanana, H. (1999). The effects of infant mortality on fertility revisited: new evidence from Latin America. Demography, 36(1), 41-58. http://dx.doi.org/10.2307/2648133

Pempel, F. C. (1993). Relative cohort size and fertility: the socio-political context of the Easterlin effect. American Sociological Review, 58(4), 496-514. http://dx.doi.org/10.2307/2096073

Pempel, F. C., \& Peters, E. H. (1995). The Easterlin effect. Annual Review of Sociology, 21, 163-194. http://dx.doi.org/10.1146/annurev.soc.21.1.163

Rosero, B. L. (1996). Nuptiality trends and fertility transition in Latin America. The Fertility Transition in Latin America, 135-150.

Saad, P. M. (2011). Demographic trends in Latin America and the Caribbean. Population Aging. Is Latin America Ready.

Waldorf, B., \& Byun, P. (2005). Meta-analysis of the impact of age structure on fertility. Journal of Population Economics, 18(1), 15-40.

Wright, R.E., \& Maxim, P. S. (1987). Canadian fertility trends: a further test of the Easterlin hypothesis. Review of Canadian Sociology and Anthropology, 24(3), 339-357.

\section{Notes}

Note 1. Relative cohort size, the proportion of younger workers to older workers in the labor force, has been used in numerous tests of the Easterlin hypothesis for countries that have already undergone the demographic transition for individual countries. Exceptions to these single country studies are Gauthier and Hatzius (1997) and Jeon and Shields (2005), which use panel data for industrialized countries. Another exception is Macunovich (2000), which uses cross sectional data for a single year.

Note 2. The 34 countries include Argentina, Antigua and Barbuda, Aruba, The Bahamas, Barbados, Belize, Bolivia, Brazil, Chile, Colombia, Costa Rica, Cuba, Dominican Republic, Ecuador, EI Salvador, Grenada, Guatemala, Guyana, Haiti, Honduras, Jamaica, Mexico, Nicaragua, Panama, Paraguay, Peru, Puerto Rico, St. Lucia, St. Vincent and the Grenadines, Suriname, Trinidad and Tobago, Uruguay, Venezuela, RB, and Virgin Islands (U.S.). We exclude Cayman Islands, Dominica, Netherlands Antilles and St. Kitts and Nevis because data of fertility rate and relative cohort size are unavailable for these countries.

Note 3. For example, the effect of infant mortality in year $t$ is the sum of changes observed between 1975 and year $t$. 